\title{
Fat substitution and food intake: effect of replacing fat with sucrose polyester at lunch or evening meals
}

\author{
BY JACQUI R. COTTON ${ }^{1}$, VICTORIA J. BURLEY ${ }^{1}$, JAN A. WESTSTRATE \\ AND JOHN E. BLUNDELL ${ }^{1}$ \\ ${ }^{1}$ BioPsychology Group, Psychology Department, University of Leeds, Leeds LS2 $9 \mathrm{JT}$ \\ ${ }^{2}$ Unilever Research Laboratorium, Vlaardingen, The Netherlands
}

(Received 22 December 1994 - Revised 24 July 1995 - Accepted 8 August 1995)

\begin{abstract}
The objective of the present study was to determine the effect of replacement of fat by sucrose polyester (SPE) within a lunch or evening meal on subsequent energy intake and appetite control. The $2 \times 2$ design was intended to examine the effect on appetite of reducing the total energy and fat content of a meal (lunch or dinner) by replacement of natural fat with $55 \mathrm{~g} \mathrm{SPE}$. The effects were monitored by measuring motivation to eat or actual food consumption during the remainder of the test day (day 1 ) and throughout the following day (day 2$)$. The $2 \times 2$ design yielded four conditions which were a control meal $(5192 \mathrm{~kJ}$, $73.2 \mathrm{~g}$ fat) and a fat-replaced meal ( $3305 \mathrm{~kJ}, 54.6 \mathrm{~g} \mathrm{SPE}, 24 \mathrm{~g}$ fat) at midday (lunch) or in the early evening (dinner). No significant differences were seen in ad lib. energy intake after the test meals on day 1 or day 2. Certain differences were detected in fat intake on day 2 but these did not suggest nutrient compensation in response to the fat replacement. Subjective assessment of motivation to eat did not indicate that the fat-reduced meal had a weaker satiating efficiency than the control meal. A reduction in fat content, using fat replacement, did not reduce the satiating efficiency of a test meal given at lunch or dinner. No energy or macronutrient compensation occurred following the reduction in energy or fat intake during the rest of the test day or during the whole of the next day.
\end{abstract}

Sucrose polyester: Satiety: Appetite

There is a general consensus among health educators concerning the need to reduce the amount of fat consumed. The UK government's most recent target is for a reduction of fat intake to less than $35 \%$ of food energy by the year 2005 (Department of Health, 1992). Most recent Office of Population Censuses and Surveys UK statistics reveal that the adult population consumes on average about $40 \%$ of energy (non-alcoholic) as fat (Gregory $e t$ al. 1990).

Consumption of a large amount of dietary fat could result in weight gain and possibly obesity. An association between the incidence of obesity and the percentage of energy consumed as fat has been established (Dreon et al. 1988; Romieu et al. 1988; Klesges et al. 1992; Tucker \& Kano, 1992). Dietary fat has been found to have a strong positive correlation with total energy intake (Gregory et al. 1990). Clinical trials have demonstrated that if subjects are exposed to a diet high in fat (food quotient $<0.85$ ) an overconsumption of energy can result (Lissner et al. 1987; Tremblay et al. 1989). Cross-sectional studies have revealed that the obese are more likely to have a greater proportion of fat in their diets (Tremblay et al. 1989; George et al. 1990; Tucker \& Kano, 1992).

The relationship between dietary fat and satiety is currently under investigation in order to assess the impact that the above dietary recommendations may have on appetite control. In general dietary fat, joule for joule, has been found to have a relatively weak effect on satiety (Blundell \& Burley, 1990; Blundell et al. 1993). However, the relationship is not 
clear and results are conflicting. The different experimental outcomes may be attributed to the distinct methodologies which have been employed. Certain studies have found that fat has an equivalent satiating efficiency to carbohydrate and that manipulations of energy using fat are accurately compensated for by later adjustments in intake (Foltin et al. 1990; Rolls et al. 1992). Other studies have demonstrated that addition of a fat supplement to a basic breakfast has no effect on subsequent intake whilst an isoenergetic carbohydrate supplement exerts a short-term effect on appetite control (Cotton et al. 1994). A study by Hulshof et al. (1993) showed no effects of different amounts of fat eaten in various physical states at breakfast on energy intake during the remainder of the day or the day after. Birch et al. (1993) found incomplete compensation when preloads contained larger amounts of fat. Additionally, high-fat foods have been demonstrated to have a relatively weak effect on satiation (bringing a meal to a close) and satiety (inhibition over further consumption) in comparison with high-carbohydrate foods in lean men (Cotton et al. 1994), and obese women (Lawton et al. 1993) or in comparison with high-sucrose foods (Green et al. 1993). The consumption of large amounts of fat does not appear to bring about any increase in satiety. This is supported by the work of Mattes et al. (1988) who found that greater compensation occurred in response to a covert reduction in the energy content of a meal rather than to an increase in the size of the meal. Caputo \& Mattes (1992) also found that compensation was stronger for covert dilution than supplementation. It is conceivable that the addition of fat (a fat-plus manipulation) may induce different influences on satiety than the removal of fat (a fat-minus manipulation). This work suggests that compensation will be more effective for decreased food intakes than for increased food intakes.

The use of fat substitutes provides an elegant technique for achieving the desired reduction in fat intake. If fat has a relatively weak effect on satiety, then replacement of fat by a fat substitute or fat mimetic should reduce the amount of fat consumed without significantly weakening the effect of that food on satiety. In a previous study sucrose polyester (SPE) was substituted for fat at a breakfast meal and subjects were free to compensate for the reduction in energy over the remainder of the day. Indeed, subjects demonstrated good compensation for the larger $34 \mathrm{~g}$ fat replacement (Burley \& Blundell, 1992; Rolls et al. 1992) at least to the high dose of SPE. Conversely in two recent studies fat intake was reduced by $55 \mathrm{~g}$ using SPE substitution over $1 \mathrm{~d}$ by making small SPE substitutions on either four (meal) or five (snack) eating occasions. In these studies intake on day 1 was fixed whilst day 2 intake was ad lib. There was no compensation on day 2 for the incremental reduction in energy and fat on day 1 nor was there any sign of these fat replacements altering motivation to eat (Cotton et al. 1993).

In the present study the single manipulation of fat was made within one meal offered either at lunch or dinner. Theoretically, a substitution made at lunch-time leaves a further $10 \mathrm{~h}$ during the same day in which any potential energy compensation can take place. However, fat replacement at a dinner meal limits the possibility for compensation to the remaining $4 \mathrm{~h}$ of that day. In both circumstances of course, subjects can compensate during the whole of the following day. The monitoring of these potential compensatory effects simultaneously throws light on the satiating capacity of natural fat and the effect on satiation of replacing fat by SPE.

\section{METHODS}

\section{Subjects}

Sixteen lean (BMI 19-26 $\mathrm{kg} / \mathrm{m}^{2}$ ) healthy males were recruited from the campus at the University of Leeds. Subject characteristics can be found in Table 1. All subjects were screened before study entry to exclude the subjects with a tendency to restrict food intake. Dietary restraint was assessed by the three-factor eating questionnaire (Stunkard \& 
Table 1. Characteristics of the subjects participating in the present study

\begin{tabular}{|c|c|c|c|c|c|c|c|c|c|c|}
\hline \multirow[b]{2}{*}{ No. } & \multirow{2}{*}{$\begin{array}{l}\text { Height } \\
\text { (m) }\end{array}$} & \multirow{2}{*}{$\begin{array}{l}\text { Weight } \\
(\mathrm{kg})\end{array}$} & \multirow{2}{*}{$\underset{\left(\mathrm{kg} / \mathrm{m}^{2}\right)}{\text { BMI }}$} & \multirow{2}{*}{$\begin{array}{c}\text { Age } \\
\text { (years) }\end{array}$} & \multirow[b]{2}{*}{ EIT* } & \multirow{2}{*}{$\begin{array}{c}\text { Body } \\
\text { fat } \\
(\%)\end{array}$} & \multicolumn{2}{|c|}{ BMR $†$} & \multicolumn{2}{|c|}{ EEEः } \\
\hline & & & & & & & $\mathbf{k J}$ & (kcal) & $\mathrm{kJ}$ & (kcal) \\
\hline 1 & 1.75 & $72 \cdot 2$ & $23 \cdot 6$ & 26 & 1 & $14 \cdot 8$ & 7837 & (1873) & 11757 & $(2810)$ \\
\hline 2 & $1 \cdot 80$ & $82 \cdot 7$ & $25 \cdot 5$ & 26 & 9 & $17 \cdot 7$ & 8904 & (2128) & 13355 & (3192) \\
\hline 3 & $1-77$ & 66.8 & $21 \cdot 3$ & 26 & 1 & $15 \cdot 5$ & 7184 & (1717) & 10778 & (2576) \\
\hline 4 & 1.80 & 83.8 & 25.9 & 24 & 2 & 18.9 & 8657 & (2069) & 12987 & (3104) \\
\hline 5 & 1.83 & 86.7 & $25 \cdot 9$ & 23 & 2 & $21 \cdot 2$ & 8414 & (2011) & 12623 & (3017) \\
\hline 6 & 1.69 & $68 \cdot 8$ & $24 \cdot 1$ & 23 & 6 & $21 \cdot 2$ & 6899 & (1649) & 10351 & (2474) \\
\hline 7 & 1.85 & 83.8 & $24 \cdot 5$ & 22 & 3 & 19.8 & 8556 & (2045) & 12837 & (3068) \\
\hline 8 & 1.82 & 76.8 & $23 \cdot 2$ & 24 & 2 & 13.8 & 8431 & (2015) & 12648 & (3023) \\
\hline 9 & 1.91 & 83.8 & 23.0 & 22 & 2 & $18 \cdot 0$ & 8732 & (2087) & 13100 & (3131) \\
\hline 10 & $1 \cdot 74$ & 78.0 & $25 \cdot 8$ & 25 & 6 & $22 \cdot 8$ & 7719 & (1845) & 11581 & $(2768)$ \\
\hline 11 & $1 \cdot 87$ & $78 \cdot 0$ & $22 \cdot 3$ & 23 & 1 & $19 \cdot 0$ & 8050 & (1924) & 12075 & (2886) \\
\hline 12 & 1.92 & $78 \cdot 2$ & $21 \cdot 2$ & 22 & 0 & $16 \cdot 9$ & 8268 & (1976) & 12401 & (2964) \\
\hline 13 & 1.76 & $59 \cdot 0$ & 19.0 & 23 & 4 & $10 \cdot 9$ & 6690 & (1599) & 10037 & (2399) \\
\hline 14 & 1.79 & $71 \cdot 3$ & $22 \cdot 3$ & 22 & 3 & $11 \cdot 5$ & 8037 & (1921) & 13665 & (3266) \\
\hline 15 & 1.90 & 90.0 & 24.9 & 22 & 2 & $18 \cdot 8$ & 9309 & (2225) & 13966 & (3338) \\
\hline 16 & $1 \cdot 81$ & 76.5 & $23 \cdot 4$ & 23 & 1 & $15 \cdot 2$ & 8263 & (1975) & 12397 & (2963) \\
\hline Mean & 1.81 & $77 \cdot 3$ & $23 \cdot 5$ & $23 \cdot 5$ & $2 \cdot 8$ & $17 \cdot 5$ & 8121 & (1941) & 12284 & (2936) \\
\hline $\mathrm{SE}$ & 0.02 & 2.03 & 0.49 & 0.38 & 0.59 & 0.94 & 180 & $(43.0)$ & 284 & $(68.1)$ \\
\hline
\end{tabular}

EIT, eating inventory test (restraint); EEE, estimated energy expenditure.

* EIT scores range from 0 to 21 with scores $>11$ indicating restraint.

$\uparrow$ Measured using a BC-300 body composition analysis system (Spacelabs Inc., Redmond, WA, USA).

† Estimated from BMR using conversion factors given by Department of Health (1991).

Messick, 1985). Subjects were given a full medical examination before being allowed to take part in the study. Participants had an alcohol intake of less than 29 units per week and were prepared to sign confidentiality agreements. All participating subjects therefore were normal-weight, non-smokers with no reported medical condition or illness. Food preferences were checked in order to eliminate subjects with a specific dislike for any of the foods used in this study. Our use of sixteen subjects is based on experience of studies of this type over a number of years. This number of subjects is adequate to detect statistical differences with manipulations of dietary energy equal to or less than those made in the present study.

\section{Design and test meals}

The design of the present study was approved by the ethics committee of the United Leeds Hospitals Trust. Subjects attended four $2 \mathrm{~d}$ test sessions (conditions A-D). Conditions A and $B$ tested the effect of consuming a control meal or a fat-replaced meal containing SPE at lunch-time on subsequent energy intake for the rest of that day, and the following day. Conditions $\mathrm{C}$ and $\mathrm{D}$ tested the effects of consuming the same meals in the early evening. Subsequent food intake on the same day and through the next day was monitored to determine any compensatory response. A comparison of conditions A, B, C and D would reveal information about the timing of consumption of a reduced energy (reduced-fat meal) delivery of an energy- and fat-reduced meal on appetite. Conditions were administered to each subject in a counterbalanced order. On each first test day subjects were provided with a standard breakfast composed of cereal and toast. On conditions $\mathrm{C}$ and $\mathrm{D}$ subjects were also given a standard lunch of shepherds pie, peas, yoghurt and biscuits. Subjects were 
given either the control test meal (conditions A and C) or the SPE test meal (conditions B and D). The nutritional composition of set meals used at the lunch (conditions $A$ and B) and dinner ( $C$ and $D$ ) is set out in Table 2. Fat replacement was achieved by using SPE which is a mixture of hexa-, hepta- and octaesters of sucrose with edible long-chain fatty acids (Bergholz, 1992). SPE is not digested by pancreatic lipases (Drewnowksi, 1990). SPE was incorporated into six different products: croissant, processed cheese, margarine, potato crisps, milk (also made into custard), and apple pie. The manipulated meal consisted of two croissants filled with margarine, cheese and ham, crisps, a glass of milk and apple pie with custard. The protein and carbohydrate contents of the test meals were constant. On day 1 after subjects had consumed the test meals they were provided with a pre-recorded selection of foods in a snack box to consume ad lib. for the rest of the day. The snack boxes contained a range of foods including bread rolls, cheese, margarine and jam portions, crisps, biscuits, soups, and Heinz Snack Pot meals. On day 2, subjects were provided with three ad lib. meals at breakfast, lunch and dinner. The SPE foods were provided by Unilever Research Laboratorium, Vlaardingen, The Netherlands.

\section{Ratings}

Subjective motivation to eat (hunger, desire to eat, fullness and prospective consumption) was assessed by repeated administration of $100 \mathrm{~mm}$ visual analogue ratings scales throughout days 1 and 2. The palatability of the test meals was also assessed by $100 \mathrm{~mm}$ visual analogue scales completed immediately after consumption. At the end of both days 1 and 2, subjects completed a questionnaire to record general appetite and mood state over the whole day (end-of-day questionnaire).

\section{Procedure}

Subjects were scheduled to come to the Human Appetite Research Unit on four occasions for two consecutive test days at 1-week intervals. Subjects were usually tested on the same days of the week on each occasion. On arrival at the Appetite Unit on the first test day of each week subjects' health and their previous day's activities were checked. Subjects were rescheduled to return on another occasion if their behaviour or food intake on the previous evening had been irregular in any way. On all conditions subjects were provided with a standard breakfast composed of cereal and toast on test day 1. Subjects were required to eat all of the breakfast and were then free to leave the Unit until lunch. Subjects were permitted to consume one drink of tea or coffee during the morning provided they had the same drink on the morning of each test day 1.

On conditions $\mathbf{A}$ and $\mathbf{B}$ subjects returned at lunch-time and were given one of the manipulated meals (containing fat or SPE) which they were required to consume. Following this all subsequent food intake was ad lib. A range of snack foods were given to the subject to be taken away for ad lib. consumption during the rest of the day. Subjects were instructed to eat exclusively from the foods provided. Subjects were required to keep a record of all foods consumed including any beverages taken throughout the afternoon and evening. Subjects were also told to return all remaining foods including wrappers or containers the next day when a full inventory and thorough check of food consumed was made.

In conditions $C$ and $D$, subjects returned to the unit at 12.30 hours and were given a standard lunch to consume. They left the laboratory after finishing the lunch and during the afternoon they were allowed one hot beverage provided they consumed the same on the other afternoon when the test meal manipulation was administered in the evening. At 17.30 hours subjects returned and were then given the manipulated meal, after which they were given a smaller box of food for ad lib. consumption during the evening. All foods consumed 
Table 2. Nutritional composition of control and sucrose polyester (SPE) test meals*

\begin{tabular}{|c|c|c|c|c|c|c|c|}
\hline \multirow[b]{2}{*}{ Food } & \multicolumn{3}{|c|}{ Control meal } & \multicolumn{4}{|c|}{ SPE meal } \\
\hline & $\mathrm{kJ}$ & (kcal) & Fat (g) & $\mathrm{kJ}$ & (kcal) & Fat (g) & SPE (g) \\
\hline Croissant $\times 2$ & 1347 & (322) & $16 \cdot 4$ & 757 & (181) & 1.4 & 18 \\
\hline Processed cheese $40 \mathrm{~g}$ & 552 & $(132)$ & 12 & 280 & $(67)$ & $4 \cdot 8$ & $7 \cdot 2$ \\
\hline Lean ham $50 \mathrm{~g}$ & 188 & $(45)$ & 1 & 188 & $(45)$ & 1 & 0 \\
\hline Margarine $10 \mathrm{~g}$ & 318 & (76) & 8 & 159 & (38) & $4 \cdot 6$ & $4 \cdot 6$ \\
\hline Crisps $25 \mathrm{~g}$ & 561 & (134) & 8 & 427 & $(102)$ & $5 \cdot 4$ & 4 \\
\hline Milk $300 \mathrm{~g}$ & 824 & $(197)$ & 11 & 452 & $(108)$ & 1 & 11 \\
\hline Apple pie $\times 1$ & 1038 & $(248)$ & 14 & 770 & $(184)$ & 6 & 7 \\
\hline Custard with test milk $75 \mathrm{~g}$ & 364 & $(87)$ & $2 \cdot 75$ & 272 & $(65)$ & $0 \cdot 2$ & $2 \cdot 75$ \\
\hline $\begin{array}{l}\text { Total } \\
\% \text { Energy in meal }\end{array}$ & 5192 & (1241) & $\begin{array}{l}73 \cdot 2 \\
53\end{array}$ & 3305 & (790) & $\begin{array}{l}24 \\
27\end{array}$ & $54 \cdot 6$ \\
\hline
\end{tabular}

* Identical meals were presented at either lunch or dinner on day 1.

were recorded and leftover foods returned the next day, as for conditions A and B. On the day following each of these test days all food intake was ad lib. The subjects were provided with a pre-weighed breakfast, lunch and evening meal. Breakfast was composed of cereal, croissants and orange juice; lunch, a selection of sandwich-type foods; and dinner, pasta bolognese, salad, yoghurt and biscuits. Each meal contained an ample supply of food in excess of anticipated consumption. Intake from these meals was weighed to the nearest $0.1 \mathrm{~g}$. Subjects were permitted to have one hot beverage in the middle of the morning and one in the afternoon provided they consumed the same each week. After the evening meal any further food and drink consumed was recorded in a food diary. Subjects were trained in the use of a food diary before the start of the experiment.

Energy and macronutrient intakes from test meals, snack boxes and food diaries were determined using manufacturers' product information and a computerized version of the UK food tables plus supplements (Comp-eat 4.0.; Lifeline Nutrition Services Ltd, London).

\section{Statistical analysis}

As the procedure on day 1 differed between conditions $A$ and $B$, and $C$ and $D$, the visual analogue rating scale data collected on day 1 were analysed in two sections, with conditions $\mathrm{A}$ and $\mathrm{B}$ being compared separately from $\mathrm{C}$ and $\mathrm{D}$. Day 1 ratings were analysed using a 2-way ANOVA with test-meal type and time as within-subjects factors. Data from day 2 were also analysed using a 2-way ANOVA with the previous day's conditions and time as the within-subjects factors. The palatability and end-of-day questionnaires were analysed using a 2-way fully repeated measures ANOVA with test meal and time of test meal as the factors.

Energy and macronutrient intakes from snack boxes were compared using paired $t$ tests. Energy and macronutrient intakes over the whole of day 1 were analysed using a 2-way ANOVA with test-meal type and time of test meal as within-subjects factors. An ANOVA was used to investigate whether there was an effect of the order in which subjects were given the conditions on energy intakes. For day 2, breakfast, lunch, dinner, food diary and total intakes were also analysed using a 2-way ANOVA. Post-hoc paired Student's $t$ tests were carried out to further investigate any significant mean effects from the ANOVA. SAS PC (Statistical Analysis Systems, Cary, NC, USA) and Minitab Data Analysis Software were used for the statistical procedures. 


\section{RESULTS}

\section{Ratings}

Motivation to eat. Analysis of the subjective ratings assessing motivation to eat from day 1 and day 2 revealed a main effect of time. This was the case for desire to eat, hunger, fullness and prospective consumption. For example, the effect of time on hunger ratings on day 1 was $F 24.67$, (df 8, 120, $P<0.01$ ) and on day 2 (pre- and post-meal and pre-bed values) was $F 63.18$ (df 6,90, $P<0.01$ ). The ratings showed little effect of the manipulated meals except the hunger ratings for conditions $\mathrm{A}$ and $\mathrm{B}$ when subjects rated themselves as more hungry after consuming the control meal at lunch time $(F 4.69$, df $1,15, P<0.05$ ) (see Fig. 1). No further effects were disclosed on day 1 on conditions $\mathrm{C}$ and $\mathrm{D}$ or among all four conditions on day 2 (Figs. 2 and 3). The temporal profiles of the desire to eat, fullness and prospective consumption ratings were similar to those of the hunger ratings.

Palatability. No differences were detected between the control and SPE test meals in the post-meal ratings. Subjects found the control and SPE test meals to be similarly tasty, pleasant, satisfying and filling.

End of day questionnaire. Before bed on both days 1 and 2, subjects completed an endof-day questionnaire. The test-meal manipulation and time of administration (lunch or dinner) had no effect on general mood (anxious, content), appetite (urge to eat, hunger, fullness) or thirst over the whole of day 1 or day 2 .

\section{Energy and macronutrient intakes}

Energy. Energy intakes from the snack box did not differ after the SPE and control meals were given at lunch-time $(t 0.83$, df $15, P=0.42)$ or dinner $(t 0.35$, df $15, P=0.73)$. In order to investigate the possible compensation during the rest of the day for the fat replacement incurred at lunch or dinner-time the degree of compensation was computed for each subject according to the formula:

energy intake after the SPE lunch/dinner-energy intake after the control lunch/dinner difference in energy generated by the fat manipulation at lunch/dinner

Taking these values, the average compensation during the rest of the day for the lunch-time manipulation was $-15 \cdot 2 \%$ and for the early evening meal manipulation was $-11 \cdot 1 \%$. Both of these values were significantly different from $100 \%$ compensation $(t 6.23$, df 15 , $P<0.01 ; t 3.41$, df $15, P<0.01$ respectively) but not significantly different from $0 \%$ ( $t 0.83$, df $15, P=0.42 ; t 0.34$, df $15, P=0.74$ ). These results suggest that little or no compensation occurred for the reduction in energy which resulted from the fat replacement in one meal given at lunch-time or in the early evening. Over the whole of day 1 , subjects consumed approximately $1654 \mathrm{~kJ}$ (400 kcal) more when given the control meal compared with when they received the SPE meal (Table 3). A 2-way ANOVA revealed a main effect of meal type $(F 34.28$, df $1,15, P<0.01)$ on total energy intake for day 1 . This reflected the test-meal manipulation.

On day 2, energy intakes were analysed using a 2-way ANOVA. No significant difference was detected in energy consumed on the day after the manipulated meals. The only exception to this was at the lunch meal (day 2) where the ANOVA revealed an effect of group (the time subjects received the meals, lunch $v$. dinner). Table 4 shows that subjects ate more at lunch on day 2 when they had been given the test meals in the evening on the previous day. Post-hoc $t$ tests carried out among energy intakes from the $a d l i b$. lunch disclosed that 


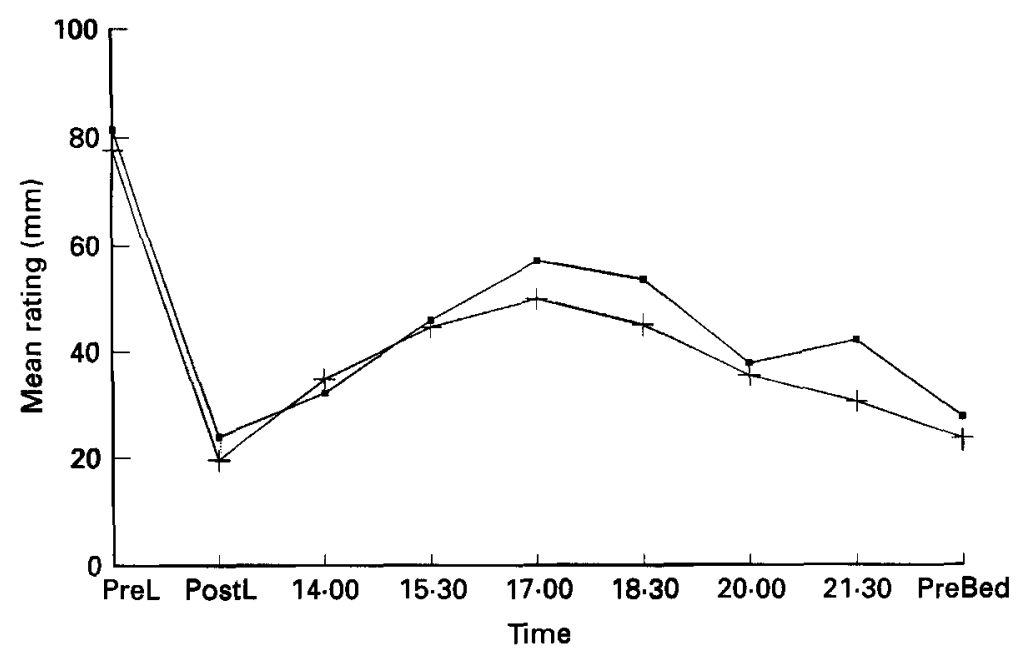

Fig. 1. Temporal profile of hunger ratings from just before lunch (PreL) until just before bed (PreBed) in subjects consuming a lunch meal containing fat $(\boldsymbol{D})$ or a similar lunch meal in which some of the fat was replaced by sucrose polyester $(+)$. For details of meals and procedures, see Table 2 and pp. 547-549. Values are means for sixteen subjects. Main effect of time $(F 24.67 ;$ df 8,$120 ; P<0.01)$ and of lunch type $(F 4.69 ; \mathrm{df} 1,15 ; P<0.05)$.

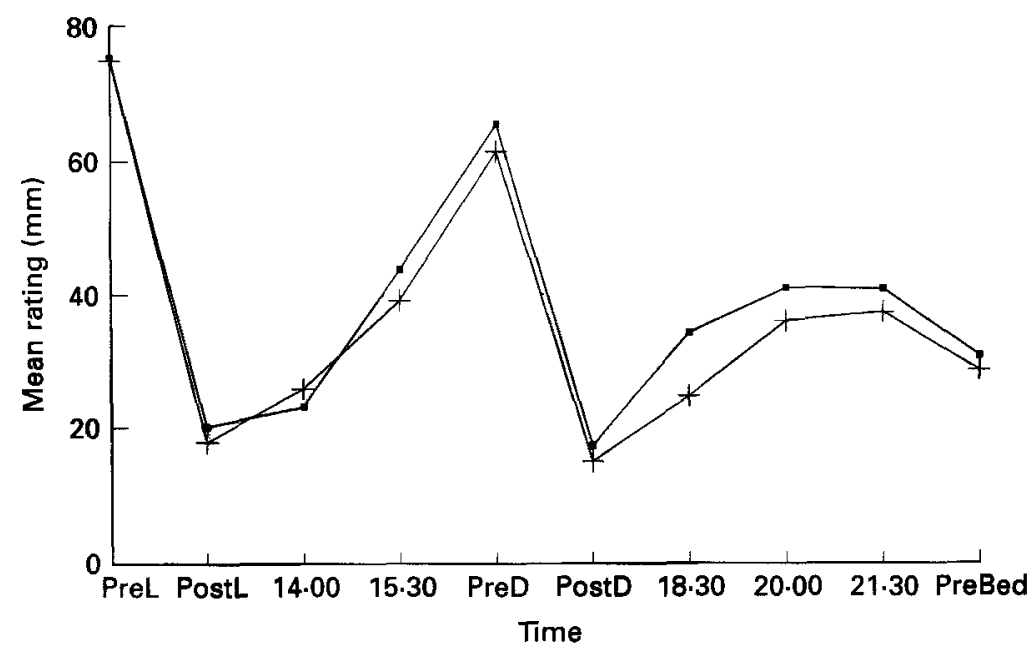

Fig. 2. Temporal profile of hunger ratings from just before lunch (PreL) until just before bed (PreBed) in subjects consuming a dinner (D) meal containing fat ( $)$ or a similar dinner meal in which some of the fat was replaced by sucrose polyester $(+)$. For details of meals and procedures, see Table 2 and pp. 547-549. Values are means for sixteen subjects. Main effect of time ( $F 35.41$; df 9,$135 ; P<0.01)$.

subjects ate significantly less when they received the SPE meal at lunch-time compared with when they received the SPE meal $(t 3$, df $15, P<0.01)$ and the control meal $(t 2.76$, df 15 , $P<0.01$ ) at dinner-time (Table 3 ).

\section{Macronutrients}

Protein, carbohydrate and fat intakes from the food box did not differ between conditions $A$ and $B$ or between conditions $C$ and D on day 1 . Protein and carbohydrate intakes on day 2 did not differ at any eating occasion across the day or over the whole day. 


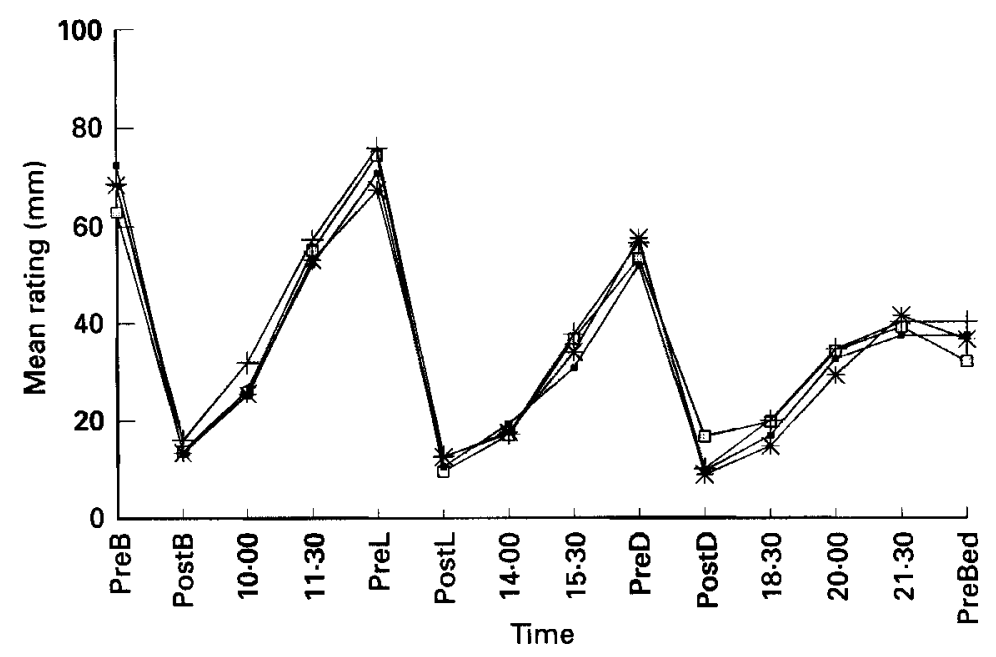

Fig. 3. Temporal profile of hunger ratings from just before breakfast (PreB) until just before bed (PreBed) in subjects who had consumed lunch (L) or dinner (D) meals containing fat or sucrose polyester (SPE) on the previous day. ( $\square$ ), Control lunch; $(+)$, SPE lunch; $\left({ }^{*}\right)$, control dinner; $(\square)$, SPE dinner. For details of meals and procedures, see Table 2 and pp. 547-549. Values are means for sixteen subjects. Main effect of time (F 63.18; df 6,$90 ; P<001$ ).

For fat intakes on day 2, no differences were found which related to the consumption of natural fat or SPE foods on day 1 . However, some statistically significant effects were noted which depended on the time of the administration of the fixed meal on day 1 . Subjects consumed more fat at lunch (day 2 ) when they had received the test-meal manipulation in the evening $(F 8 \cdot 24$, df $1,15, P<0 \cdot 01)$. Analysis of the fat intakes over the whole of day 2 also showed an effect of group. Post-hoc tests revealed that subjects consumed more fat the day after they received the low-fat SPE meal in the evening compared with the day after they had received the SPE meal at lunch $(t 3.09$, df $15, P<0.01)$.

\section{DISCUSSION}

The present study was designed to evaluate the effect on appetite of replacement of natural fat $(55 \mathrm{~g}$ ) by SPE during single meals (given at lunch or dinner-time) on one day (day 1). The effects of these meal manipulations were monitored by subjective ratings of appetite, end-of-day questionnaires and the measured free consumption of food for the rest of day 1 and throughout the whole of day 2 . In addition after every experimental day an end-ofday questionnaire was administered with an open section at the bottom for reporting any side-effects of the meals.

These single-meal manipulations did not give rise to any measurable differences in food consumption during the rest of day 1 (when subjects were eating freely from take-home boxes of foods) or throughout day 2 when subjects were allowed to eat freely at meal times in the Human Appetite and Research Unit. Energy intake following the manipulated meals did not differ for either day 1 or day 2. Therefore energy intakes (including the manipulated meals) were significantly different. Energy intakes for day 1 and for days 1 and 2 combined were significantly lower after subjects had received the SPE foods on day 1 . This meant that subjects did not compensate for the energy reduction brought about by the replacement of fat by SPE on day 1 by eating more food afterwards. The replacement of fat by SPE did 
Table 3. Energy intakes ( $k J$, with $k c a l$ in parentheses) over 2 d by subjects receiving lunch or dinner meals in which fat was replaced by sucrose polyester (SPE)*

(Mean values and standard deviations for sixteen subjects)

\begin{tabular}{|c|c|c|c|c|c|c|c|c|}
\hline \multirow[b]{3}{*}{ Eating occasion } & \multicolumn{8}{|c|}{ Condition } \\
\hline & \multicolumn{2}{|c|}{ Control lunch } & \multicolumn{2}{|c|}{ SPE lunch } & \multicolumn{2}{|c|}{ Control dinner } & \multicolumn{2}{|c|}{ SPE dinner } \\
\hline & Mean & SD & Mean & SD & Mean & SD & Mean & SD \\
\hline \multicolumn{9}{|l|}{ Day 1} \\
\hline Breakfast & $\begin{array}{c}2088 \\
(499)\end{array}$ & - & $\begin{array}{l}2088 \\
(499)\end{array}$ & - & $\begin{array}{l}2088 \\
(499)\end{array}$ & E & $\begin{array}{l}2088 \\
(499)\end{array}$ & - \\
\hline Lunch & $\begin{array}{c}5192 \\
(1241)\end{array}$ & - & $\begin{array}{c}3350 \\
(790)\end{array}$ & - & $\begin{array}{l}3866 \\
(924)\end{array}$ & - & $\begin{array}{l}3866 \\
(924)\end{array}$ & - \\
\hline Dinner & - & E & - & - & $\begin{array}{c}5192 \\
(1241)\end{array}$ & E & $\begin{array}{l}3350 \\
(790)\end{array}$ & $\overline{-}$ \\
\hline Box & $\begin{array}{c}7745 \\
(1851)\end{array}$ & $\begin{array}{l}1887 \\
(451)\end{array}$ & $\begin{array}{c}7230 \\
(1782)\end{array}$ & $\begin{array}{l}1377 \\
(329)\end{array}$ & $\begin{array}{l}3849 \\
(920)\end{array}$ & $\begin{array}{l}1958 \\
(468)\end{array}$ & $\begin{array}{c}3636 \\
(869)\end{array}$ & $\begin{array}{l}1623 \\
(388)\end{array}$ \\
\hline Beverages & $\begin{array}{l}184 \\
(44)\end{array}$ & $\begin{array}{l}335 \\
(80)\end{array}$ & $\begin{array}{c}96 \\
(23)\end{array}$ & $\begin{array}{l}113 \\
(27)\end{array}$ & $\begin{array}{c}75 \\
(18)\end{array}$ & $\begin{array}{c}92 \\
(22)\end{array}$ & $\begin{array}{l}305 \\
(73)\end{array}$ & $\begin{array}{c}540 \\
(129)\end{array}$ \\
\hline Total & $\begin{array}{c}15210 \\
(3635)\end{array}$ & $\begin{array}{l}1971 \\
(471)\end{array}$ & $\begin{array}{c}12950 \\
(3095)\end{array}$ & $\begin{array}{l}1402 \\
(335)\end{array}$ & $\begin{array}{c}15071 \\
(3602)\end{array}$ & $\begin{array}{l}1992 \\
(476)\end{array}$ & $\begin{array}{c}13201 \\
(3155)\end{array}$ & $\begin{array}{l}1561 \\
(373)\end{array}$ \\
\hline \multicolumn{9}{|l|}{ Day 2} \\
\hline Breakfast & $\begin{array}{l}3749 \\
(896)\end{array}$ & $\begin{array}{c}958 \\
(229)\end{array}$ & $\begin{array}{l}3669 \\
(877)\end{array}$ & $\begin{array}{c}912 \\
(218)\end{array}$ & $\begin{array}{l}3879 \\
(927)\end{array}$ & $\begin{array}{l}1038 \\
(248)\end{array}$ & $\begin{array}{l}3799 \\
(908)\end{array}$ & $\begin{array}{c}891 \\
(213)\end{array}$ \\
\hline Lunch & $\begin{array}{c}5255 \\
(1256)\end{array}$ & $\begin{array}{l}1259 \\
(301)\end{array}$ & $\begin{array}{c}5159 \\
(1233)\end{array}$ & $\begin{array}{l}1205 \\
(288)\end{array}$ & $\begin{array}{c}5527 \\
(1321)\end{array}$ & $\begin{array}{l}1046 \\
(250)\end{array}$ & $\begin{array}{c}5870 \\
(1403)\end{array}$ & $\begin{array}{c}983 \\
(235)\end{array}$ \\
\hline Dinner & $\begin{array}{c}3874 \\
(926)\end{array}$ & $\begin{array}{l}1473 \\
(352)\end{array}$ & $\begin{array}{l}3695 \\
(883)\end{array}$ & $\begin{array}{l}1155 \\
(276)\end{array}$ & $\begin{array}{l}3427 \\
(819)\end{array}$ & $\begin{array}{c}996 \\
(238)\end{array}$ & $\begin{array}{c}3439 \\
(822)\end{array}$ & $\begin{array}{c}837 \\
(200)\end{array}$ \\
\hline Diary & $\begin{array}{l}1163 \\
(278)\end{array}$ & $\begin{array}{l}1067 \\
(255)\end{array}$ & $\begin{array}{l}1188 \\
(284)\end{array}$ & $\begin{array}{l}1105 \\
(264)\end{array}$ & $\begin{array}{l}1318 \\
(315)\end{array}$ & $\begin{array}{l}1464 \\
(350)\end{array}$ & $\begin{array}{l}1444 \\
(345)\end{array}$ & $\begin{array}{l}1008 \\
(241)\end{array}$ \\
\hline Total & $\begin{array}{c}14046 \\
(3357)\end{array}$ & $\begin{array}{l}1736 \\
(415)\end{array}$ & $\begin{array}{c}13711 \\
(3277)\end{array}$ & $\begin{array}{c}2469 \\
(590)\end{array}$ & $\begin{array}{c}14150 \\
(3382)\end{array}$ & $\begin{array}{l}2720 \\
(650)\end{array}$ & $\begin{array}{c}14552 \\
(3478)\end{array}$ & $\begin{array}{l}2490 \\
(595)\end{array}$ \\
\hline
\end{tabular}

* For details of meals and procedures, see Table 2 and pp. 547-549.

not appear to produce any increased drive to eat. No adverse reactions to the test meals were reported during or after the study.

The effects of the fat replacement were also monitored by means of subjective ratings scales (for hunger, fullness etc.) which have often been shown to be sensitive indicators of nutrient differences in foods (e.g. Cotton et al. 1994) or differences in the energy consumed in lean (Green et al. 1993) and obese (Lawton et al. 1993) subjects. These ratings did not show any increase following the replacement of fat by SPE at any occasion on day 1 or throughout the whole of day 2 . Indeed, on day 1 hunger ratings were significantly lower for the rest of the day after consuming the SPE meal at lunch-time. Moreover, the end-of-day questionnaire, in which subjects assessed how they felt over the entire day, did not reveal any perceived differences in hunger, fullness etc, between the experimental manipulations. Consequently these ratings did not disclose any increases in drive to eat or enhanced feelings of hunger following the replacement of fat by SPE. It is particularly important to note that the manipulated reduction in fat did not generate any specific response to seek out or eat fatty foods later.

Taken together these results indicate that this degree of reduction of fat $(53 \%$ to $27 \%$ in the meal or $43 \%$ to $28 \%$ in the energy intake up to and including the manipulated meal) 
Table 4. Fat intakes ( $g$ ) over $2 d$ by subjects receiving lunch or dinner meals in which fat was replaced by sucrose polyester $(S P E)^{*}$

(Mean values and standard deviations for sixteen subjects)

\begin{tabular}{|c|c|c|c|c|c|c|c|c|}
\hline \multirow[b]{3}{*}{ Eating occasion } & \multicolumn{8}{|c|}{ Condition } \\
\hline & \multicolumn{2}{|c|}{ Control lunch } & \multicolumn{2}{|c|}{ SPE lunch } & \multicolumn{2}{|c|}{ Control dinner } & \multicolumn{2}{|c|}{ SPE dinner } \\
\hline & Mean & SD & Mean & SD & Mean & SD & Mean & SD \\
\hline \multicolumn{9}{|l|}{ Day 1} \\
\hline Breakfast & 11.8 & - & 11.8 & - & $11 \cdot 8$ & - & $11 \cdot 8$ & - \\
\hline Lunch & $73 \cdot 2$ & - & $24 \cdot 0$ & - & $39 \cdot 4$ & - & $39 \cdot 4$ & - \\
\hline Dinner & - & - & - & - & $73 \cdot 2$ & - & $24 \cdot 0$ & - \\
\hline Box & 67.3 & $23 \cdot 4$ & $70-4$ & 16.0 & $43 \cdot 8$ & $21 \cdot 3$ & $42 \cdot 0$ & $20 \cdot 5$ \\
\hline Beverages & 0.8 & 0.6 & $0 \cdot 6$ & 0.6 & 0.4 & $0-4$ & 0.9 & $1 \cdot 3$ \\
\hline Total & $153 \cdot 1$ & $23 \cdot 5$ & $106-8$ & $16 \cdot 1$ & $168 \cdot 7$ & $21 \cdot 6$ & $118 \cdot 2$ & $19 \cdot 9$ \\
\hline \multicolumn{9}{|l|}{ Day 2} \\
\hline Breakfast & $30 \cdot 6$ & $13 \cdot 6$ & $27 \cdot 7$ & $13 \cdot 4$ & $33 \cdot 6$ & $13 \cdot 9$ & $34 \cdot 2$ & 12.8 \\
\hline Lunch & $54 \cdot 7$ & $19 \cdot 7$ & $52 \cdot 1$ & 20.5 & $59 \cdot 0$ & $14 \cdot 4$ & 67.0 & $13 \cdot 3$ \\
\hline Dinner & $27 \cdot 4$ & $16 \cdot 8$ & $21 \cdot 6$ & $8 \cdot 1$ & $19 \cdot 4$ & 6.8 & $20 \cdot 5$ & $5 \cdot 2$ \\
\hline Diary & 11.7 & $12 \cdot 4$ & 11.2 & $12 \cdot 3$ & $15 \cdot 4$ & 21.9 & $16 \cdot 4$ & $15 \cdot 8$ \\
\hline Total & $124 \cdot 4$ & $23 \cdot 6$ & $112 \cdot 8$ & $35 \cdot 3$ & $127 \cdot 8$ & $32 \cdot 9$ & $138 \cdot 1$ & $28 \cdot 6$ \\
\hline
\end{tabular}

* For details of meals and procedures, see Table 2 and pp. 547-549.

did not produce any apparent biological reaction that could be measured. Subjects did not appear to be able to detect any consequences of the replacement of fat by SPE either immediately after the meal itself, during the rest of the day on which the manipulation was made, or for the entire following day. Subjects did not disclose any differences in their subjective perceptions of appetite or in their pattern of eating behaviour. This suggests that the use of fat replacers (such as SPE) to reduce fat energy in foods whilst preserving their gustatory and textural qualities could provide a useful strategy to allow people to reduce overall fat intake without compromising appetite control. Their attained level of approximately $32 \%$ fat in the daily intake would meet dietary guidelines. It should be realized, however, that the use of fat replacers such as SPE may also have nutritional effects that are less positive e.g. a reduced absorption of fat-soluble micronutrients.

These results indicate that a large replacement of fat $(55 \mathrm{~g})$ by SPE at a single meal (midday or early evening) did not produce any biological response detectable through the psychological and behavioural measures used. The outcome is quite consistent with that of a parallel study in which the degree of substitution was spread across an entire day and included substitutions in either three main meals or in five snacks (Cotton et al. 1993).

In both of these studies the reduction of fat from approximately $40 \%$ to approximately $30 \%$ energy was similar. These different ways of reducing fat intake have produced similar outcomes. It could, of course, be questioned whether these experimental procedures are sufficiently sensitive to detect any nutritional manipulations of this type. However, in a further study, recently completed, in which the level of fat was reduced from 30 to $20 \%$ energy (in small substitutions spread across the day), subjects did respond by eating more on the following day. Consequently the procedures are sensitive and the techniques are able to detect an increased drive to eat.

These results do not agree with the findings of Rolls et al. (1992) and Burley \& Blundell (1992) where compensation for a reduction in energy did occur within $1 \mathrm{~d}$ in response to 
a breakfast manipulation. This provokes the interesting possibility that a large fat replacement occurring at lunch or dinner may not give sufficient time within that day for some metabolic effect of fat to take place which would result in compensation being demonstrated.

One question might concern the short-term nature of this type of study. It is possible that the lack of a response to substitution within a single day would give way to an increased drive to eat if the substitution was repeated for days or weeks? At the present time these results suggest that a reduction in the level of fat to approximately $30 \%$ of total energy intake per day does not generate a potent behavioural response, but in substitutions below $30 \%$ energy intake may become so low $(<1.4$ times estimated resting metabolic rate) in these individuals that for normal functioning there is a shortage of fuel. This argument is consistent with the belief that $40 \%$ of fat energy in a diet constitutes a high fat intake. This amount of fat would not be expected to exert a marked action on appetite and therefore some of this fat could be omitted or replaced without weakening the control of appetite. These present results, together with others (Cotton et al. 1994; Shide et al. 1995), draw attention to the way in which dietary fat may have a weak effect on appetite control and encourage the development of strategies to develop fat-reduced or fat-replaced foods in order to reduce overall levels of fat consumption.

The experimental work in this study was supported by the Biotechnology and Biological Sciences Research Council (AFRC, FG 24/544) and by Unilever Research Laboratorium, Vlaardingen, The Netherlands. The authors would like to acknowledge the assistance of Jos van Duuren and Willy Dubelaar of the Unilever Research Laboratorium (Vlaardingen, The Netherlands) for taking care of the provision of the experimental foods.

\section{REFERENCES}

Bergholz, C. M. (1992). Safety evaluation of Olestra, a non-absorbed, fat-like fat replacement. Critical Reviews in Food Science and Nutrition 32, 141-146.

Birch, L. L., McPhee, L. S., Bryant, J. L. \& Johnson, S. L. (1993). Childrens' lunch intake: effects of mid morning snacks varying in energy density and fat content. Appetite 20, 83-94.

Blundell, J. E. \& Burley, V. J. (1990). Evaluation of the satiating power of dietary fat in man. In Progress in Obesity Research 1990, pp. 453457 [Y. Oomura, S. Tarui, S. Inoue and T. Shimazu, editors]. London: John Libbey.

Blundell, J. E., Burley, V. J., Cotton, J. R. \& Lawton, C. L. (1993). Dietary fat and the control of energy intake: weak inhibitory action of fat on meal size and post-meal satiety. American Journal of Clinical Nutrition 57, Suppl. $5,772 \mathrm{~S}-778 \mathrm{~S}$.

Burley, V. J. \& Blundell, J. E. (1992). Evaluation of the action of a non-absorbable fat on appetite and energy intake in lean healthy males. In Obesity in Europe 91, pp. 63-65 [G. Ailhaud, B. Guy-Grand, M. Lafontan and D. Ricquier, editors]. London: John Libbey.

Caputo, F. A. \& Mattes, R. D. (1992). Human dietary responses to covert manipulations of energy, fat and carbohydrate in a midday meal. American Journal of Clinical Nutrition 56, 36-43.

Cotton, J. R., Burley, V. J. \& Blundell, J. E. (1993). Effect on appetite of replacing natural fat with sucrose polyester in meals or snacks across one whole day. International Journal of Obesity 17, Suppl. 2, 47.

Cotton, J. R., Burley, V. J. \& Blundell, J. E. (1994). Dietary fat and appetite: similarities and differences in the satiating effect of meals supplemented with either fat or carbohydrate. Journal of Human Nutrition and Dietetics 7, 11-24.

Department of Health (1991). Dietary Reference Values for Food Energy and Nutrients for the United Kingdom. Report on Health and Social Subjects no. 41. London: H.M. Stationery Office.

Department of Health (1992). The Health of the Nation: a Strategy for Health in England. London: H.M. Stationery Office.

Dreon, D. M., Frey Hewitt, B., Ellsworth, N., Williams, P. T., Terry, R. B. \& Wood, P. D. (1988). Dietary fat: carbohydrate ratio and obesity in middle aged men. American Journal of Clinical Nutrition 47, 995-1000.

Drewnowski, A. (1990). The new fat replacements. A strategy for reducing fat consumption. Postgraduate Medicine 87, 111-114. 
Foltin, R. W., Fischman, M. W., Moran, T. H., Rolls, B. J. \& Kelly, T. H. (1990). Carolic compensation for lunches varying in fat and carbohydrate content by humans in a residential laboratory. American Journal of Clinical Nutrition 52, 969-980.

George, V., Tremblay, A., Deprés, J. P., Leblanc, C. \& Bouchard, C. (1990). Effect of dietary fat content on total and regional adiposity in men and women. International Journal of Obesity 14, 1085-1094.

Green, S. M., Burley, V. J. \& Blundell, J. E. (1993). Evaluation of the contribution of sucrose-containing foods to the control of appetite. Comparison of the capacity of sucrose and fat to satisfy hunger. European Journal of Clinical Nutrition 48, 547-555.

Gregory, J., Foster, K., Tyler, H. \& Wiseman, M. (1990). The Dietary and Nutritional Survey of British Adults. London: H.M. Stationery office.

Hulshof, T., DeGraaf, C. \& Weststrate, J. A. (1993). The effects of preloads varying in physical state and fat content on satiety and energy intake. Appetite 23, 273-286.

Klesges, R. C., Klesges, L. M., Haddock, C. K. \& Eck, L. H. (1992). A longitudinal analysis of the impact of dietary intake and physical activity on weight change in adults. American Journal of Clinical Nutrition 55, 818-822.

Lawton, C. L., Burley, V. J. \& Blundell, J. E. (1993). Dietary fat and appetite control in obese subjects: weak effects on satiation and satiety. International Journal of Obesity 17, 409-416.

Lissner, L., Levitsky, D. A., Strupp, B. J., Kalkwarf, H. J. \& Roe, D. A. (1987). Dietary fat and the regulation of energy intake in human subjects. American Journal of Clinical Nutrition 46, 886-892.

Mattes, R. D., Pierce, C. B. \& Friedman, M. I. (1988). Daily caloric intake of normal weight adults: response to changes in dietary energy density of a lunchtime meal. American Journal of Clinical Nutrition 88, 214-219.

Rolls, B. J., Pirraglia, P. A., Jones, M. B. \& Peters, J. C. (1992). Effects of Olestra, a non-caloric fat substitute, on daily energy and fat intakes in lean men. American Journal of Clinical Nutrition 56, 84-92.

Romieu, I., Willett, W. C., Stampfer, M. J., Colditz, G. A., Sampson, L., Rosner, B., Hennekens, C. H. \& Speizer, F. E. (1988). Energy intake and other determinants of relative weight. American Journal of Clinical Nutrition 47, 406-412.

Shide, D. J., Callallero, B., Reidelberger, R. \& Rolls, B. J. (1995). Accurate energy compensation for intragastric and oral nutrients in lean males. American Journal of Clinical Nutrition 61, 754-764.

Stunkard, A. J. \& Messick, S. (1985). The three-factor eating questionnaire to measure dietary restraint, distribution and hunger. Journal of Psychosomatic Research 29, 71-83.

Tremblay, A., Plourde, G., Després, J. P. \& Bouchard, C. (1989). Impact of dietary fat content and fat oxidation on energy intake in humans. American Journal of Clinical Nutrition 49, 799-805.

Tucker, L. A. \& Kano, M. J. (1992). Dietary fat and body fat: a multivariate analysis of 205 adult females. American Journal of Clinical Nutrition 56, 616-622. 